\title{
Un debate complejo: la técnica de reproducción humana asistida post mortem desde la perspectiva comparada*
}

\section{Marisa Herrera**}

\section{RESUMEN}

El presente ensayo tiene por objeto problematizar y profundizar desde una perspectiva comparada la especial técnica de reproducción humana asistida como lo es la fertilización post mortem. Para este fin, se toman, a modo de disparador, recientes planteos judiciales esgrimidos en tres ordenamientos jurídicos con realidades y legislaciones bien diferentes como lo son Argentina, Francia y Gran Bretaña, a los cuales también se debe sumar España siendo que uno de estos precedentes involucra a la regulación española.

PALABRAS CLAVE: Fertilización post mortem, Jurisprudencia, Derecho comparado, Derechos Humanos, Consentimiento informado.

\section{ABSTRACT}

This essay is intended to problematize and deepen, from a comparative perspective, the special technique of assisted human reproduction as it is the post-mortem fertilization. For this end, we present recent judicial approaches made in three legal systems with realities and legislations very different, such as Argentina, France and Great Britain, to which it is also necessary to add Spain because one of these precedents involves the Spanish regulation.

KEY WORDS: post-mortem fertilization, jurisprudence, comparative law, human rights, informed consent

\footnotetext{
"Una primera versión resumida de este trabajo ha sido enviada para su publicación a la revista Indret. Aqui se amplian y profundizan varias de las líneas teóricas esgrimidas en aquélla oportunidad. Artículo recibido el 27 de agosto de 2016 y aceptado el 13 de octubre de 2016.

** Investigadora Independiente del Conicet. Profesora de Derecho de Familia y Sucesiones, Facultad de Derecho de la Universidad de Buenos Aires. marisaherrera12@gmail.com
} 


\section{SUMARIO}

1. Introducción

2. La justicia argentina contemporánea

3. Los problemas del consentimiento presunto o desde el más allá

4. La justicia francesa

5. La justicia inglesa

6. Breves palabras de cierre

\section{Introducción}

El desarrollo de la ciencia observa un crecimiento exponencial. Un ejemplo elocuente es lo que acontece en el campo de las técnicas de reproducción humana asistida (en adelante TRHA), a tal punto que se le dedica un número específico y especial a las diferentes problemáticas que rodean a esta práctica médica de mayor presencia en la realidad social regional y mundial.

Si bien aquí se dedica particular atención a lo que acontece en América Latina, a los fines de profundizar lo que acontece allí se ha elegido una cuestión puntual: la fertilización post mortem ${ }^{1}$ (FPM) desde una perspectiva comparada, es decir, compulsando el desarrollo en otros ordenamientos jurídicos por fuera del ámbito latinoamericano.

Para tal fin, se han seleccionado tres precedentes del 2016. Uno compromete el derecho argentino; los dos restantes, al derecho francés, con fuerte impacto en el derecho español y en el derecho inglés. ¿A qué responde este interés por el desarrollo jurisprudencial en países con diferente desarrollo legislativo y cultura jurídica? Demostrar que ciertos conflictos pueden generar las mismas complejidades, e incluso, corresponder a soluciones jurídicas similares.

¿A qué se debe el interés por la fecundación post mortem? A la diversidad de aristas que presenta esta particular cuestión que rodea a las TRHA cuando ese le interpela interpelada por un hecho traumático como lo es el fallecimiento de una persona. Precisamente, varias y bien disimiles situaciones de fecundación post mortem se han presentado en distintos puntos del globo. Este panorama fáctico-jurídico es hábil para actualizar y profundizar sobre una temática que aún resta camino por recorrer.

En esta oportunidad, nos centramos en tres casos jurídicos que no agotan las situaciones que pueden plantearse y que, incluso, podrían generar igual o

\footnotetext{
${ }^{1}$ ¿Fertilización o filiación post mortem? Si bien se la conoce como fertilización post mortem, lo cierto es que tam-
} bién involucra la filiación post mortem, de alli que la F como sigla podria encuadrar o representar ambas vertientes. 
mayores debates desde el punto de vista ético como lo sería si se entrecruza la FPM con otra figura polémica dentro del campo de las TRHA como la gestación por sustitución. No es el objetivo del presente ensayo agotar el estudio de la FPM sino, por el contrario, sentar las bases para construir una legislación al respecto que aporten planteamientos jurídicos más cotidianos pero no por ello complejos, hábiles para detectar los elementos estructurales de esta TRHA en especial.

Como punto de partida obligado, cabe destacar que el estudio de la fertilización post mortem no es ajeno a un interrogante central que atraviesa la gran mayoría de los conflictos que integran el ámbito objetivo o de aplicación del derecho de familia: la tensión ancestral entre autonomía de la voluntad y orden público. Más específicamente tratándose de las TRHA, cuál debería ser el límite al desarrollo, avance y perfeccionamiento de la ciencia y su razonabilidad. ¿Acaso todo lo científicamente posible es ética y jurídicamente viable? ¿Cuáles son los intereses y derechos en juego en la FPM? Responder estas inquietudes es básico a los fines de alcanzar una regulación equilibrada y respetuosa de los derechos humanos comprometidos.

Para responder a estos interrogantes, nos centraremos en los avances y debates generados en el derecho argentino. Se colocará el eje en la noción de "consentimiento informado" entendida como "la declaración de voluntad suficiente efectuada por el paciente, o por sus representantes legales en su caso, emitida luego de recibir, por parte del profesional interviniente, información clara, precisa y adecuada". ${ }^{2}$ Ésta debe ponerse por escrito tal como lo prescribe el Código Civil y Comercial argentino, en vigencia desde el primero de agosto de 2015 para todo lo relativo a la filiación derivada de la reproducción asistida. ${ }^{3}$ La FPM involucra, en definitiva, una cuestión filial con respecto al niño que pueda nacer de un procedimiento con estas características, destacada por el

\footnotetext{
${ }^{2}$ Véase artículo 5 de la ley 26.529 de Derechos del Paciente en su Relación con los Profesionales e Instituciones de la Salud, sancionada por el parlamento argentino en el año 2009 y reafirmada en el artículo 59 del Código Civil y Comercial.

${ }^{3}$ El artículo 560 establece: "El centro de salud interviniente debe recabar el consentimiento previo, informado y libre de las personas que se someten al uso de las técnicas de reproducción humana asistida. Este consentimiento debe renovarse cada vez que se procede a la utilización de gametos o embriones". El artículo 561 se refiere a la "Forma y requisitos del consentimiento"; dispone: "La instrumentación de dicho consentimiento debe contener los requisitos previstos en las disposiciones especiales, para su posterior protocolización ante escribano público o certificación ante la autoridad sanitaria correspondiente a la jurisdicción. El consentimiento es libremente revocable mientras no se haya producido la concepción en la persona o la implantación del embrión". Por último, el artículo 562, referido a la voluntad procreacional, consigna que "Los nacidos por las técnicas de reproducción humana asistida son hijos de quien dio a luz y del hombre o de la mujer que también ha prestado su consentimiento previo, informado y libre en los términos de los artículos 560 y 561, debidamente inscripto en el Registro del Estado Civil y Capacidad de las Personas, con independencia de quién haya aportado los gametos".
} 
fallecimiento de una persona que exteriorizó -de manera expresa o presuntala voluntad procreacional, columna vertebral de este tipo o causa fuente filial. ${ }^{4}$

En definitiva, en el presente ensayo se pretende desentrañar el papel que cumple el consentimiento informado en los casos de FPM, profundizándose sobre su contenido y materialidad a la luz de los diferentes supuestos que puede involucrar esta tipología especial de reproducción asistida que coloca en crisis el derecho filial clásico.

\section{La justicia argentina contemporánea}

El 13 de junio de 2016 una noticia periodística acaparó la atención de varios medios periodísticos argentinos. Se trata de un señor que falleció en un accidente ferroviario ocurrido el 13 de septiembre de 2011 cuya esposa, acompañada por sus suegros (padres del fallecido) solicitaron judicialmente la extracción de material genético. Un juez hizo lugar a la petición. Años más tarde, la viuda pretende recurrir a un procedimiento de reproducción asistida para tener un hijo con dicho material. Ante la negativa del centro de salud especializado, pidió a la justicia la correspondiente autorización para llevar adelante la práctica médica. El juzgado nacional en lo civil con competencia exclusiva en asuntos de familia número 87 de la Capital Federal,5 el 5 de mayo de 2016 hizo lugar a la acción.6 En consecuencia, autorizó el uso del material del esposo fallecido hace casi 5 años.

¿Es correcta la interpretación de la jueza argentina en esta oportunidad? ¿Cuáles son los intereses en juego? ¿Cuáles pueden ser los peligros de una interpretación benigna o a favor en la situación fáctica planteada? ¿Cuál sería la interpretación correcta a la luz de los principios que emanan del nuevo Código Civil y Comercial argentino ante la falta de regulación expresa de la FPM?

Antes de responder brevemente estos interrogantes, es de interés dejar en claro que este planteo no es el primero, sino que ha habido uno anterior que no tuvo la repercusión mediática que el caso más reciente y que se analiza en

188 esta oportunidad.

\footnotetext{
${ }^{4}$ Dispone el artículo 558 del Código Civil y Comercial que "La filiación puede tener lugar por naturaleza, mediante técnicas de reproducción humana asistida, o por adopción. La filiación por adopción plena, por naturaleza o por técnicas de reproducción humana asistida, matrimonial y extramatrimonial, surten los mismos efectos, conforme a las disposiciones de este Código. Ninguna persona puede tener más de dos vínculos filiales, cualquiera sea la naturaleza de la filiación".

${ }^{5}$ También conocida como ciudad de Buenos Aires.

6 "'N. O. C. P. s/Autorización', Juzgado Nacional en lo Civil, No. 87, 05/05/2016", El Dial. [Consulta: 10 de junio, 2016]. Disponible en: https://www.eldial.com/nuevo/lite-jurisprudencia-detalle.asp?id=39674\&tbase $=14$ cth $=u$
} 
Nos referimos al caso resuelto por la Cámara Tercera de Apelaciones en lo Civil y Comercial, Minas de Paz y Tributario de Mendoza (07 de agosto de 2014). ${ }^{7}$ En este también se hizo un pedido de transferencia post mortem a favor de una mujer que había conseguido una autorización judicial para extraer material genético del cuerpo de su esposo fallecido. Aquí los argumentos esgrimidos fueron, básicamente, los siguientes: a) el acceso integral a las TRHA que recepta la ley 26.862 del 2013, que involucra más que la cobertura médica; $b$ ) el derecho a tener hijos biológicos a través del acceso a las TRHA que se derivaría del derecho a la integridad personal, libertad personal y a la vida privada y familiar; c) se le resta toda eficacia a la falta de consentimiento ${ }^{8}$ y d) que sólo las leyes que regulan la ablación y trasplantes de órganos y tejidos han establecido el respeto a la voluntad expresa del donante en vida, por tratarse de aspectos que la legislación considera ligados a los atributos de la personalidad y a la autodeterminación.

¿En el fallo más reciente se siguen los mismos argumentos? ¿Cambia? En dado caso, ¿en qué sentido? ¿A la luz de lo dispuesto en el nuevo Código Civil y Comercial, que no sólo regula de manera expresa la filiación derivada de las TRHA, sino que además se ocupa en los artículos 55 y 56 a los actos de disposición sobre el propio cuerpo?

Contabilizándose el último precedente del 5 de mayo de 2016, el panorama jurisprudencial argentino es joven. Además, se encuentran integrado por un total de cinco sentencias. La primera data del 21 de noviembre de 2011; se trata de una sentencia dictada por el Tribunal de Familia número 3 de Morón, Provincia de Buenos Aires, que involucra una pareja que se encuentra en procedimiento de reproducción asistida. En el ínterin, al señor le descubren una enfermedad oncológica y al tiempo fallece. Meses después, la mujer solicita al centro de salud la transferencia del material genético criopreservado y ante la negativa inicia un pedido de autorización judicial. ${ }^{9}$

El segundo, es el fallo mendocino ya mencionado. El tercero es un precedente del Juzgado Nacional en lo Civil número 3 resuelto el 3 de noviembre de

\footnotetext{
${ }^{7}$ Tercera Cámara de Apelaciones en lo Civil, Comercial, Minas, de Paz y Tributario-Mendoza, "S., M. C. s. Medida autosatisfactiva", Rubinzal Culzoni. Disponible en: http://www.rubinzalonline.com.ar/fallo/9702/

${ }^{8}$ Esto se da por dos razones. Por un lado, por la falta de derechos de personas cuya existencia se haya extinguido (para el ordenamiento jurídico) que puedan esgrimirse en contra de pretensiones de personas de existencia visible. $\mathrm{Ni}$ en el ámbito de la sucesiones puede alegarse que el ordenamiento jurídico otorgue "derecho" al causante de que se cumplan sus disposiciones mortis causa, pues los beneficiarios pueden renunciar a recibir las herencias o legados. Además, la legislación protege y legitima a esos beneficiarios o a otros preteridos, no al causante.

9 "Tribunal Familiar núm. 3 Morón, 21 de noviembre, 2011, 'G., A. P'.", Revista de Derecho de Familia, No. 3, Buenos Aires, Abeledo Perrot, 2012, p. 119.
} 
2014. Una mujer solicitó obtener las muestras de semen de su marido fallecido $\mathrm{y}$, a la par, la cobertura médica del tratamiento post mortem. ${ }^{10} \mathrm{El}$ cuarto fallo resuelto el 30 de diciembre de 2015 del Juzgado Civil, Comercial, Lab. y de Minería número 4 de Santa Rosa, La Pampa involucra un supuesto en el que existen embriones conformados por material genético del marido fallecido y óvulos donados que pretenden transferirse a la cónyuge supérstite con la consecuente cobertura médica. ${ }^{11}$ El quinto y último es el que aquí se analiza de manera sintética a modo de disparador -junto a dos casos planteados en el derecho comparado-. La finalidad es exponer los conflictos que genera la FPM, y los diferentes supuestos fácticos y jurídicos que se pueden plantear.

De los cinco precedentes, dos de ellos involucran de manera previa la autorización judicial de extracción de gametos post mortem; en otros dos, el fallecimiento acontece con posterioridad a la extracción de material consentida por quien transitaba por un procedimiento de TRHA, y en uno sólo de ellos se contaba con embriones conformados con material genético de la persona fallecida y óvulo donado. ¿Estas diferencias tienen alguna incidencia en la resolución de los casos? ¿En qué sentido y sobre la base de qué argumentos? ¿Importa que los primeros tres precedentes hayan sido resueltos bajo el régimen civil derogado y, por el contrario, el último fallo acá en estudio -junto con el fallo oriundo de la Pampa - lo sea ya vigente el Código Civil y Comercial?

Algo tienen en común todos estos precedentes: dan cuenta de la falencia que se deriva del silencio legislativo o, en otras palabras, de la importancia de contar con reglas jurídicas claras al respecto. Esta situación se presentará en la realidad con mayor frecuencia a la par del mayor desarrollo y acceso a las TRHA.

En este sentido, debe tomarse en cuenta que el entonces anteproyecto de reforma -antecedente directo del Código Civil y Comercial- regulaba de manera expresa la FPM del siguiente modo:

Filiación post mortem en las técnicas de reproducción humana asistida. En caso de muerte del o la cónyuge o conviviente de la mujer que da a luz, no hay vínculo filial entre la persona nacida del uso de las técnicas de reproducción humana asistida y la persona fallecida si la concepción en la mujer o la implantación del embrión en ella no se había producido antes del fallecimiento. No rige lo dispuesto en el párrafo anterior si se cumple con los siguientes

\footnotetext{
${ }^{10}$ Juzgado Nacional de 1a Instancia en lo Civil núm. 3, 3 de noviembre, 2014, "K. J. V. c. Instituto de Ginecología y Fertilidad y otros s/amparo", La Ley.

"Juzgado Civil, Com., Lab. y de Mineria Nº 4 de Santa Rosa, La Pampa, 30 de diciembre, 2015, "A., C. V. c/ Instituto de Seguridad Social-Sempre S/ Amparo", Colectivo Derecho de Familia. Disponible en: http://www.colectivoderechofamilia.com/fa-pcial-juz-1 ra-inst-civ-com-lab-y-mineria-no4-santa-rosa-la-pampa-fertilizacion-post-mortem/
} 
requisitos: a) la persona consiente en el documento previsto en el artículo 560 o en un testamento que los embriones producidos con sus gametos sean transferidos en la mujer después de su fallecimiento. b) La concepción en la mujer o la implantación del embrión en ella se produce dentro del año siguiente al deceso (artículo 563).

Esta normativa se quitó durante el debate parlamentario. Por lo tanto, prima un silencio legislativo en lo relativo a la filiación en el supuesto especial de la FPM. No así en el campo del derecho sucesorio, cuyo artículo 2779, referido a la capacidad para suceder, expresa que "Pueden suceder al causante [...] las nacidas después de su muerte mediante técnicas de reproducción humana asistida, con los requisitos previstos en el artículo 561".

Como se puede observar, el Código Civil y Comercial prevé de manera restrictiva la capacidad de heredar de la persona que naciere como consecuencia de una fecundación post mortem siempre que exista consentimiento informado en los términos que regula la normativa civil y comercial. ¿Qué sucedería si el primer procedimiento de reproducción asistida fracasara? Al no poder contarse nuevamente con otro consentimiento informado, no sería posible llevar adelante un nuevo tratamiento por ausencia de voluntad procreacional debidamente exteriorizada en un consentimiento informado y formal. Esta limitación da cuenta del carácter restrictivo de la normativa sucesoria en análisis, lo cual habilitaría a concluir que esta previsión habría quedado en el texto por omisión de quitarla, cuando así se hizo con el mencionado artículo 563 proyectado.

Por otra parte, cabe destacar que este articulado proyectado y evaporado del texto finalmente aprobado también generaba críticas muy acertadas. En primer lugar, hubiera dejado afuera de la FPM a cuatro de los cinco casos planteados en la jurisprudencia argentina. Es decir, sólo se hubiera permitido el supuesto resuelto por la jueza pampeana al tratarse de embriones. El resto de los supuestos comprometidos deberían haberse rechazado, porque se trataba de gametos (ya fueran extraídos en vida o post mortem), no de embriones. ¿Esta era una postura legislativa acorde con el desarrollo de la ciencia y, en particular, el debate -ya sorteado en varios países, no así en Argentina- en torno a la naturaleza jurídica del embrión no implantado?

El Código Civil y Comercial se perdió una valiosa oportunidad de regular el tema en análisis por presiones de la Iglesia católica. Sin embargo, la quita del articulado durante el debate parlamentario ha sido acertada. Permitir la FPM sólo ante la existencia de embriones in vitro constituye una opción legislativa sumamente restrictiva, es decir, absolutamente contraria a la idea de que el embrión no es persona. Debe tener, en materia de FPM, el mismo tratamiento 
jurídico que los gametos, de conformidad con la doctrina que emana de la Corte Interamericana de Derechos Humanos en el resonado fallo Artavia Murillo y otros contra Costa Rica, del 28 de noviembre de 2012 y reafirmado en el fallo del 26 de febrero de 2016 en el proceso de seguimiento o cumplimiento de sentencia. ${ }^{12}$

En otras palabras, si se hubiera sancionado el código tal como estaba proyectado, se hubiera incurrido en una manifiesta contradicción, no sólo a la luz de la jurisprudencia convencional citada, sino también del propio Código Civil y Comercial. Éste último remite a una ley especial para la regulación del embrión in vitro. Se admite entonces que no es persona y debería estar regulado en la legislación civil, o en el artículo 20 del mismo Código, el cual entiende por concepción el plazo máximo y mínimo de duración de un embarazo: hay persona recién a partir de la concepción (artículo 19) como sinónimo de embarazo y siempre sujeto al nacimiento con vida (artículo 21). También se habilita la revocación del consentimiento informado hasta antes de producida la transferencia del embrión en el cuerpo de una persona (artículo 561).

En esta misma línea, la ley 26.862 de Acceso Integral a las TRHA prevé la cobertura de la criopreservación y donación de embriones. Para ello, se debe partir de la idea de que los embriones no son persona, de lo contrario, no se podrían criopreservar y mucho menos donar.

Por todo esto, excluir del texto proyectado la filiación derivada por fecundación post mortem, tal como se la pretendía regular, fue, en definitiva, una decisión legislativa acertada. Ahora bien, el silencio legislativo no sería la postura más adecuada dada la importancia de la ley para dar previsibilidad y colaborar en la pacificación de relaciones humanas. ¿Qué debería decir entonces una futura normativa al respecto? ¿Ello podría replicarse o utilizarse para actualizar el debate en otros ámbitos jurídicos comparados?

\section{Los problemas del consentimiento presunto o desde el más allá}

192 Veamos el siguiente ejemplo hipotético que involucraría otro acto personalísimo familiar más común que las TRHA. Hoy es el día en que Ana contraerá matrimonio con su novio de toda la vida. Camino al registro civil, el auto que la

\footnotetext{
12 Véase Kemelmajer de Carlucci, Aida, Herrera, Marisa y lamm, Eleonora, "La Corte Interamericana de Derechos Humanos controla, sin concesión alguna, el cumplimiento de sus decisiones", La Ley, 2016, p. 357. GIL Dominguez, Andrés, "El caso 'Artavia Murillo II': la Corte Interamericana de Derechos Humanos determina con precisión la fuerza normativa de la convencionalidad aplicada a un caso concreto", Under Constitucional. [Consulta: 7 de septiembre, 2016]. Disponible en: http://underconstitucional.blogspot.com.ar/2016/04/el-caso-artavia-murillo-ii-la-corte.html
} 
conducía hasta allí hace una pésima maniobra, el rodado da varios giros y ella fallece. Nadie duda de que la intención de Ana era contraer matrimonio con Juan; pero tampoco hay duda de que Ana y Juan no han contraído matrimonio.

El consentimiento, la exteriorización o declaración de la voluntad constituye un acto de suma relevancia en el campo civil, máxime cuando se trata de derechos personalísimos como el matrimonio, o tener un hijo por técnicas de reproducción humana asistida. En estas decisiones confluyen dos vertientes o aspectos del consentimiento informado: a) por tratarse de una práctica médica y la relevancia de la autonomía de la voluntad en este marco y b) por la finalidad de dicha práctica, como tener un hijo, y el consentimiento informado como exteriorización de la voluntad procreacional (artículo 562), causa fuente de la filiación derivada de la reproducción asistida. Esta última es necesaria justamente por esta relevancia que tal voluntad quede materializada en un consentimiento escrito.

En total consonancia con esta supremacía de la voluntad, en el campo de los derechos personalísimos, el citado artículo 56 del Código Civil y Comercial, referido a los actos de disposición sobre el propio cuerpo, expresa:

Están prohibidos los actos de disposición del propio cuerpo que ocasionen una disminución permanente de su integridad o resulten contrarios a la ley, la moral o las buenas costumbres, excepto que sean requeridos para el mejoramiento de la salud de la persona, y excepcionalmente de otra persona, de conformidad a lo dispuesto en el ordenamiento jurídico. [...] La ablación de órganos para ser implantados en otras personas se rige por la legislación especial. El consentimiento para los actos no comprendidos en la prohibición establecida en el primer párrafo no puede ser suplido, y es libremente revocable. ${ }^{13}$

De este modo, así como la ablación de órganos constituye una excepción a la regla, la extracción post mortem de material genético caería dentro de la regla. Es decir, no estaría alcanzada por la posibilidad de que terceros - por más interés que tengan- puedan decidir sobre un acto que depende únicamente de la voluntad de la propia persona.

\footnotetext{
${ }^{13}$ Asimismo, cabe resaltar que el artículo 55, "Disposición de derechos personalísimos", dispone: "El consentimiento para la disposición de los derechos personalísimos es admitido si no es contrario a la ley, la moral o las buenas costumbres. Este consentimiento no se presume, es de interpretación restrictiva, y libremente revocable".
} 
Esta mirada negativa en torno al consentimiento presunto también se vincula con otra el consentimiento por representación. ${ }^{14}$ ¿Qué lugar le cabe a la esposa y a los padres de la persona fallecida, herederos forzosos, en la decisión de ser padre? La respuesta debería ser: ninguna. Al respecto, en el fallo se dice que en el acta de audiencia convocada por la suscripta a la peticionante y padres del fallecido en su carácter de herederos legítimos. Asimismo, para la resolución del caso se prestó especial atención a la conformidad de los padres del fallecido como si éste fuera un elemento sobresaliente.

¿Entonces la resolución del caso hubiera sido diferente si el fallecido hubiera tenido una hija con otra mujer y ésta se hubiera opuesto a la transferencia post mortem? ¿Y si con el tiempo aparece un hijo fruto de una relación anterior -o en paralelo a su matrimonio, lo cual es fácticamente posible- y se inicia un reclamo de paternidad post mortem? ¿Este hecho obstaculizaría o incidiría de algún modo en la autorización judicial pertinente para la transferencia post mortem? Más aún. Como en el fallo en estudio, los padres del fallecido prestan conformidad a la autorización judicial. Años más tarde, ellos fallecen y sus hijos se presentan en el sucesorio conjuntamente con el niño cuya filiación se determinó post mortem. ¿Los tíos podrían interponer alguna defensa para excluir a su supuesto sobrino de intervenir en el sucesorio por derecho de representación?

De conformidad con lo expresado por el citado artículo 2279, que se refiere de manera precisa a la existencia de consentimiento informado en los términos previstos en el artículo 561, es claro que el supuesto fáctico-jurídico de fecundación post mortem que involucra el último precedente argentino no está previsto en la norma. Por lo tanto, si naciera un niño de la transferencia post mortem que autoriza la jueza de familia subrogante, no tendría capacidad para heredar. Sucede que no hay consentimiento "previo, informado y libre de las personas que se someten al uso de las técnicas de reproducción humana asistida”, como afirma el artículo 560.

Otro elemento no menor se refiere al plazo de cinco años entre que se lo194 gró la extracción post mortem por orden judicial y el fallo en análisis que hace lugar al pedido de autorización judicial de transferencia post mortem. Esto nos conduce a un debate bastante complejo y ríspido en torno a cuándo se considera que existe un plazo razonable para que el proyecto parental siga siendo

\footnotetext{
${ }^{14}$ El consentimiento por representación es un tema de gran desarrollo en el derecho español, en particular cuando se trata de personas menores de edad o con discapacidad. Como sintesis de esta cuestión, cabe traer a colación la reforma introducida por la ley 26/2015 del 28 de julio a la ley 41/2002, del 14 de noviembre, que regula la autonomía del paciente y de derechos y obligaciones en materia de información y documentación clínica.
} 
entre la cónyuge supérstite y su marido fallecido o, por el contrario, cuándo se trataría de un proyecto unipersonal para lo cual podría directamente utilizarse material genético de un banco. ¿Y si la cónyuge hubiera fallecido años después, los padres podrian haber solicitado la transferencia post mortem del material extraído por autorización judicial a otra mujer que se hubiera prestado a ello?

En lo relativo a la extracción post mortem y a la luz del ordenamiento vigente, no sería posible que un juez haga lugar a un pedido de autorización judicial de conformidad con la regla que rige en materia de actos de disposición del propio cuerpo en el artículo 56 del Código Civil y Comercial. No se prevé una excepción, como sí acontece con la regulación en materia de trasplante de órgano. ¿Debería admitirse legalmente la extracción post mortem? ¿En qué supuestos o bajo qué condiciones? Para responder a este interrogante como también, en definitiva, a todos los que genera la FPM, debería apelarse a herramientas no jurídicas.

En esta línea, sería importante contar con el aporte proveniente de otras áreas del saber, en especial la psicología, que mucho tendrían para decir sobre el tema. ¿Cuál es el papel de los padres del hijo fallecido en este supuesto proyecto de parentalidad? ¿Cómo se construye un proyecto de parentalidad post mortem cuando no fue pensado en estos términos con quien falleció? ¿Se podría tildar de "progresista" al fallo en análisis? Fácil se advierte que la cuestión es un tanto más compleja con sólo recordar que la jueza subrogante dijo:

Resta mencionar el principio de respeto por la verdad biológica que es uno de los pilares sobre los que se apoya el régimen de filiación vigente. En este punto, si bien aún no hay niño ni embrión y tampoco se ha reclamado la inscripción del niño o niña con filiación paterna, no hay duda alguna en que la peticionante hará honor a tal principio pues su intención es tener un hijo de quien fue su compañero ya que, si su deseo fuera sólo unilateral de maternidad, hubiera acudido a material heterólogo, evitando así la intervención judicial. Además, en la audiencia mantenida, me ha expresado ser consciente del desafío que significa su petición tanto para ella como para el futuro hijo, pero no dudaría en requerir orientación profesional en el momento que resulte necesario.

El progreso en el campo de la bioética debería tener muy en cuenta a modo de cimiento el respeto por la libertad, es decir, priorizar la decisión de los propios protagonistas y la aceptación de que la reproducción asistida constituye una tercera fuente filial con reglas propias, en el que la tradicional "verdad 
biológica" no tiene el mismo peso que en la filiación por naturaleza. Niño y embrión son dos cuestiones muy diferentes. El embrión se asemeja más a los gametos o material genético cuando se trata de filiación derivada de TRHA. ${ }^{15}$ Estas sí son distinciones que hacen miradas más progresistas.

\section{La justicia francesa}

Un caso que ha tenido repercusión mediática en Francia y que repercute de manera directa en España, es el que resolvió el Consejo de Estado francés el 31 de mayo de 2016. Se trata de una acción iniciada por una mujer ante un juez de référés ${ }^{16}$ del tribunal administrativo de París, con fundamento en el artículo L. 521-2 del Código de Justicia Administrativa. El objetivo es que ordenara a la Asistencia Pública -Hospital de París- y a la Agencia de Biomedicina, que adoptaran las medidas necesarias para que se exporten los gametos de su marido fallecido el 9 de julio de 2015 a un establecimiento de salud especializado español para realizar un procedimiento de reproducción asistida.

$\mathrm{Al}$ respecto, cabe señalar que la fecundación post mortem está prohibida en el ordenamiento jurídico francés. No así en el derecho español, donde la regula el artículo 9 de la ley 14/2006, dedicado al supuesto de "Premoriencia del marido". ${ }^{17}$ En el derecho francés, el artículo L. 2141-2 del Código de la salud pública expresa:

\footnotetext{
${ }^{15}$ El Código Civil y Comercial se refiere a la revocación ya sea que se trate de "concepción en la persona o la implantación del embrión". En este sentido, se puede revocar existiendo material genético o embrión.

${ }^{16}$ En Francia existen jueces de référés, es decir, jueces con competencia en medidas urgentes. No existe una palabra exactamente equivalente en la lengua española, por lo que se ha decidido mantener la denominación en el idioma de origen.

${ }^{17}$ El artículo 9 dispone: "1. No podrá determinarse legalmente la filiación ni reconocerse efecto o relación jurídica alguna entre el hijo nacido por la aplicación de las técnicas reguladas en esta Ley y el marido fallecido cuando el material reproductor de éste no se halle en el útero de la mujer en la fecha de la muerte del varón. 2. No obstante lo dispuesto en el apartado anterior, el marido podrá prestar su consentimiento, en el documento a que se hace referencia en el artículo 6.3, en escritura pública, en testamento o documento de instrucciones previas, para que su material reproductor pueda ser utilizado en los 12 meses siguientes a su fallecimiento para fecundar a su mujer. Tal generación producirá los efectos legales que se derivan de la filiación matrimonial. El consentimiento para la aplicación de las técnicas en dichas circunstancias podrá ser revocado en cualquier momento anterior a la realización de aquéllas. Se presume otorgado el consentimiento a que se refiere el párrafo anterior cuando el cónyuge supérstite hubiera estado sometido a un proceso de reproducción asistida ya iniciado para la transferencia de preembriones constituidos con anterioridad al fallecimiento del marido. 3. El varón no unido por vínculo matrimonial podrá hacer uso de la posibilidad prevista en el apartado anterior; dicho consentimiento servirá como título para iniciar el expediente del apartado 8 del artículo 44 de la Ley 20/2011, de 21 de julio, del Registro Civil, sin perjuicio de la acción judicial de reclamación de paternidad".
} 
La asistencia médica a la procreación tiene por objeto remediar la infertilidad de una pareja o evitar la transmisión al niño o a un miembro de la pareja de una enfermedad de cierta gravedad. El carácter patológico de la infertilidad debe estar médicamente diagnosticado. El hombre y la mujer que conformen la pareja deben estar vivos, en edad de procrear y consentir previamente la transferencia de embriones o la inseminación. Configuran obstáculos a la inseminación o a la transferencia de embriones el deceso de uno de los miembros de la pareja, la presentación de una demanda de divorcio o de separación de hecho o la cesación de la vida en común, así como la revocación por escrito del consentimiento por el hombre o la mujer ante el médico encargado de llevar a cabo la asistencia médica para la procreación.

Por otra parte, en lo relativo al traslado del material genético, el artículo L. 2141-1 de la misma legislación referida a la salud pública expresa:

La importación y la exportación de gametos o de tejidos germinales procedentes de un cuerpo humano son sometidos a una autorización emitida por la Agencia de biomedicina. Sólo un establecimiento, un organismo o un laboratorio titular de la autorización prevista en el artículo L 2142-1 para ejercer una actividad biológica de asistencia médica para la procreación, puede obtener la autorización prevista en este artículo. Toda violación de las prescripciones establecidas por la autorización de importación o de importación de gametos o de tejidos germinales implica la suspensión o el retiro de dicha autorización por la Agencia de Biomedicina.

El juez interviniente rechazó la demanda. La actora apeló el 8 de febrero de 2016 ante el secretario en lo Contencioso del Consejo de Estado francés. Este organismo se pronunció, el 31 de mayo de 2016 a favor de lo peticionado. Es decir, hacer lugar al traslado del material genético del esposo fallecido a un centro de salud español, dado que este país admite la FPM. ${ }^{18}$

\footnotetext{
${ }_{18}$ Para un primer acercamiento actual sobre el desarrollo de la FPM en el derecho español, véase RodRIGUEZ GuitiAn, ALMA, "La reproducción artificial post mortem en España Estudio ante un nuevo dilema jurídico", Revista Boliviana de derecho, No. 20, pp. 292-323. [Consulta: 12 de julio, 2016]. Disponible en: http://idibe.org/wp-content/ uploads/2013/09/121.pdf

Este trabajo es una actualización de una labor de investigación que desarrolla esta autora plasmada en HERRERA, MARISA, Reproducción artificial post mortem. Análisis del artículo 9 de la ley 14/2006 de 26 de mayo sobre Técnicas de Reproducción Humana Asistida, Valencia, Tirant lo Blanch, Valencia, 2013. La primera ley de reproducción
} 
Los principales argumentos o consideraciones de fondo que se esgrimen para arribar a esta solución son los siguientes:

- Como principio, se afirma que la regulación prohibitiva de la fecundación post mortem que rige en el derecho francés no viola el artículo 8 del Convenio Europeo de Derechos Humanos. Este último se refiere al respeto por la vida privada y familiar, de conformidad con el reiterado principio de "margen de apreciación de los Estados". El Tribunal Europeo de Derechos Humanos apela con mucha frecuencia a este principio en el campo de los derechos personalísimos y de las relaciones familiares, es decir, las temáticas harto sensibles.

- La legislación dispone que los gametos depositados en Francia pueden ser objeto de exportación siempre que sean destinados en el extranjero para fines no prohibidos en el territorio francés. Sin embargo, se entiende que estas disposiciones no desconocen las exigencias del mencionado artículo 8 de la Convención europea.

- Tales aseveraciones no obstaculizan que, en ciertas circunstancias particulares, la aplicación de esos principios configure una injerencia desproporcionada en los derechos garantizados por la propia Convención. En este contexto, el problema central consiste en discernir si el Código de la salud pública "configura o no una afectación manifiestamente excesiva al derecho a que se respete la vida privada y familiar de la señora CA, garantizada por el artículo 8 de la Convención europea de protección de los derechos del hombre y de las libertades fundamentales".

- La respuesta positiva se impone de conformidad con la plataforma fáctica planteada en el caso. Por lo tanto, no hay fraude por parte de la mujer que peticiona el traslado de los gametos a España. Veamos. Aquí la señora CA y su marido habían proyectado tener un hijo. Una gravedad afectó al señor MB, y el tratamiento implicaba el riesgo de dejarlo estéril. Por ello, se procedió, de manera preventiva, a extraer esperma y criopreservarlo en un centro de salud para que en un futuro pudieran someterse a TRHA. Este proyecto no pudo llevarse a cabo porque el señor MB falleció al poco tiempo. Éste había consentido expresamente que su esposa se inseminara con su material genético de manera post mortem,

asistida fue española: la Ley 35/1988, de 22 de noviembre sobre Técnicas de Reproducción Asistida. Regulaba de manera similar la cuestión de la FPM. Por ello, en el derecho español se cuenta con mayor desarrollo teórico sobre esta temática. 
en España, país de origen de la señora CA, si los intentos realizados en Francia, en vida de él, resultaran infructuosos.

- La urgencia de la petición, dado que la legislación española autoriza la fecundación post mortem dentro del año de producido el fallecimiento.

De conformidad con los argumentos sintetizados, el Consejo de Estado ordena a la Asistencia pública -Hospital Francés y Agencia de Biomedicina-que adopten las medidas necesarias a fin de permitir la exportación de gametos de MB hacia un establecimiento de salud español autorizado a practicar procreaciones médicamente asistidas, dentro de los siete días de notificada la decisión.

Como se puede observar, las prohibiciones traen consigo ciertas dificultades y paradojas, como acontece en este caso. No sólo el gasto que significa llevar adelante un procedimiento de TRHA en el extranjero, sino también el riesgo que insume todo traslado de material genético, y la angustia de someterse a una práctica invasiva como esta, en soledad o alejada del lugar de pertenencia. Máxime cuando las distancias entre los países cada vez se acortan más por la facilidad en el traslado y en la comunicación entre los establecimientos especializados. Por ende, poca utilidad o efecto prohibitivo tiene que se deniegue la fecundación post mortem en un país cuando el de al lado lo permite. En este contexto, cabría preguntarse si la prohibición de la fecundación post mortem del derecho francés debería mantenerse o si, por el contrario, en respeto por la vida privada o íntima y familiar, no sería más acorde su permisión. En ese caso, debemos preguntarnos, además, bajo qué condiciones o cómo debería ser la regulación, adelantándose que el consentimiento informado por escrito y específico o especial a la posibilidad de que se produzca el fallecimiento de quienes pretenden llevar adelante un proyecto parental por uso de las TRHA debería ocupar un lugar central.

\section{La justicia inglesa}

Más complejo aún sería el caso planteado ante la justicia londinense entre mediados del 2015 y abril del 2016, donde se permite la fecundación post mortem. ${ }^{19}$ El 15 de junio de $2015,{ }^{20}$ el Tribunal Real de Justicia de Londres se expi-

\footnotetext{
${ }^{19}$ The National Archives, "Use of sperm, or transfer of embryo, after death of men providing sperm", Human Fertilisation and Embryology Act 2008. Disponible en: http://www.legislation.gov.uk/ukpga/2008/22/section/39

20 "Judgment in proceedings challenging the decision by the HFEA to refuse permission to allow export and use of female gametes after death of the donor. Issues of consent, correct use of powers and engagement of Article 8", Family Law Week. [Consulta: 2 de julio, 2016]. Disponible en: http://www.familylawweek.co.uk/site.aspx?i=ed145462
} 
dió ante el pedido de una madre de implantarse los gametos de su hija fallecida criopreservados en una clínica de Estados Unidos. Sintéticamente, la plataforma fáctica es la siguiente.

Una mujer de 28 años (AM), hija única, falleció el 12 de junio de 2011 de cáncer. AM, sin pareja, había comenzado a realizar un procedimiento de reproducción asistida, por el cual se había procedido a criopreservar sus óvulos sin fertilizar en un centro de salud en Nueva York, Estados Unidos. Asimismo, dejó firmado un consentimiento informado que permitía el almacenamiento póstumo de esos óvulos.

Su madre (M), de 58 años de edad, resaltó que su hija, antes de morir, había manifestado su deseo de que uno o más de sus óvulos fueran implantados en ella mediante la utilización de esperma donado. Esto no fue plasmado por escrito; este es el argumento más fuerte (la falta de consentimiento informado por escrito) que sustenta la negativa del tribunal a hacer lugar al pedido. Este último había sido rechazado con anterioridad en tres oportunidades por la autoridad de aplicación en TRHA de Gran Bretaña, conocida por sus siglas en inglés como HFE. En este marco, se afirma de manera precisa "Que los gametos de una persona o células humanas no deben ser utilizados para llevar a cabo la creación de cualquier embrión in vitro a menos que exista un consentimiento efectivo por esa persona".

Por otra parte, en la sentencia se puntualiza que la HFE opinó que la expresión de deseos a la cual se refiere la madre por parte de su hija, se realizó sin información suficiente para que AM comprendiera plenamente las consecuencias de tal declaración y los temas involucrados, en especial los riesgos que se derivan para su progenitora en relación con la maternidad subrogada y las implicaciones legales de tales acuerdos.

Siguiendo esta línea argumental, se sabe que el rechazo al pedido de la señora $M$, madre de quien dejó el material genético póstumo, implicaría la destrucción de los óvulos y la frustración de los deseos de madre e hija. Por lo tanto, se interfiere en su vida privada y familiar. Sin embargo, se desestima el pedido por no haberse dado cumplimiento a los requisitos necesarios o de validez del correspondiente consentimiento informado.

La madre apeló la decisión. El Tribunal de Apelaciones de Londres dictó sentencia, el 14 de febrero $2016,{ }^{21}$ revirtiendo la negativa y, por lo tanto,

\footnotetext{
21 "Application for permission to appeal against an order dismissing the appellants' claim for judicial review of a decision of the respondent, the Human Fertilisation and Embryology Authority, where the appellants had sought to have the gametes of their daughter exported to a treatment centre in New York", Family Law Week. [Consulta: 2 de julio, 2016]. Disponible en: http://www.familylawweek.co.uk/site.aspx?i=ed159321
} 
haciendo lugar al planteo de la madre. Para resolver en este sentido, se puso de resalto que tanto la HEF como el juez interviniente habían sido demasiados estrictos: no habían tomado suficientemente en cuenta la condición terminal de AM, ni las circunstancias especiales que se daban en el caso y que la madre había esgrimido y probado. En la sentencia se explicita que "la reacción inicial fue negar el permiso, pero fui persuadido por la defensa de la señora $\mathrm{M} \mathrm{y}$ sus argumentos merecen la atención del tribunal en pleno". En este marco, se entendió que eran suficientes los argumentos brindados por la madre, que justifican la concesión del permiso centrado en las circunstancias esgrimidas y no en un enfoque indebidamente tan riguroso como el de las instancias anteriores.

El consentimiento informado formal cumple un rol esencial en el campo de la filiación derivada de las TRHA. Tendría como elemento adicional, tratándose de fecundación post mortem el ser particular o específico, al proyectarse lo que acontecería en el supuesto de fallecimiento de quien o quienes quieren ser padres. En este contexto, cabría preguntarse si sería posible apelar a la noción de consentimiento presunto y probar por diferentes medios de prueba la supuesta intención de una persona para un derecho personalísimo, como tener un hijo, mejor conocido como "voluntad procreacional". Si acaso las exigencias no deberían ser mayores cuando se trata de supuestos de FPM; si sólo sería viable permitirse la FPM cuando se trata de proyectos parentales conjuntos y no unipersonales; $y$, de manera más compleja aún, el posible entrecruzamiento entre FPM y la figura de la gestación por sustitución. ¿Acaso el "todo vale” o la falta de limitaciones a las TRHA podrían obstaculizar el derecho a gozar de los beneficios del progreso científico? ${ }^{22}$ En otras palabras, conflictos como los sintetizados en este artículo permiten reavivar el debate en torno a la noción de progreso y sus límites: si es que debería haber, en qué sentido o con qué finalidad.

\footnotetext{
${ }^{22}$ Cabe destacar que en el primer y único caso que la Corte Interamericana de Derechos Humanos se expidió sobre las TRHA, del 28 de noviembre de 2012, el caso Artavia Murillo y otros contra Costa Rica, puso de relieve que "el derecho a la vida privada y la libertad reproductiva guarda relación con el derecho de acceder a la tecnología médica necesaria ejercer ese derecho. El derecho al goce de los beneficios del progreso científico ha sido reconocido

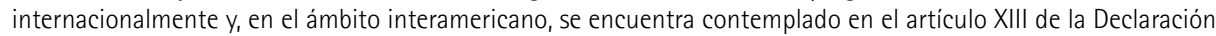
Americana y en el artículo 14.1 b) del Protocolo de San Salvador. Cabe mencionar que la Asamblea General de Naciones Unidas, en su declaración sobre este derecho, señaló la relación entre éste y la satisfacción de las necesidades materiales y espirituales de todos los sectores de la población. Por tanto, y conforme al artículo 29 b) de la Convención Americana, el alcance de los derechos a la vida privada, autonomía reproductiva y a fundar una familia, derivado de los artículos 11.2 y 17.2 de la Convención Americana, se extiende al derecho de toda persona a beneficiarse del progreso científico y de sus aplicaciones. Del derecho de acceso al más alto y efectivo progreso científico para el ejercicio de la autonomía reproductiva y la posibilidad de formar una familia se deriva el derecho a acceder a los mejores servicios de salud en técnicas de asistencia reproductiva, $y_{1}$ en consecuencia, la prohibición de restricciones desproporcionadas e innecesarias de iure o de facto para ejercer las decisiones reproductivas que correspondan en cada personas" (párrafo 150).
} 


\section{Breves palabras de cierre}

A esta altura del desarrollo de la ciencia, es sabido que el uso de las TRHA ha generado nuevas y complejas disyuntivas en el campo jurídico. Algunas de ellas deben resolverse desde la obligada perspectiva interdisciplinaria. Sin lugar a duda, la fecundación post mortem integra este grupo de conflictos donde un principio rector en el campo filial (el interés superior del niño) observa ciertas particularidades. ¿Acaso es posible evaluar este verdadero eje rector en todo lo relativo a los derechos de niños y adolescentes cuando un niño aún no ha nacido?

Algo similar acontece con otra figura compleja que integra la filiación derivada de las TRHA, como la gestación por sustitución. ¿Cuál es el deseo de los adultos -y en el caso de la fecundación post mortem, también el de sus propios familiares y herederos- y el lugar del desarrollo de la ciencia en la reproducción asistida? ¿Cómo regular cuando las situaciones fácticas son cada vez más variadas, y permiten incluso el entrecruzamiento de dos figuras con la FPM y la Gs? ¿Limitar la aceptación jurídica de la FPM en determinados supuestos conculcaría la noción de progreso y pluralismo que, en definitiva, ha permitido el desarrollo y perfeccionamiento de las TRHA? En caso afirmativo, ¿en qué supuestos y bajo qué fundamentos razonables que respeten los derechos humanos involucrados?

Parecería ser un error bastante común de quienes no están formados en la perspectiva de los derechos humanos y nos adjetivan de progresistas a quienes estamos a favor de la pluralidad de formas de organización familiar, entender que aludir a los derechos humanos implica desatender, omitir o ningunear a la legislación civil o de salud, según el ordenamiento que se trate. Nada más alejado de ello. Todo lo contrario, la constitucionalización del derecho civil ${ }^{23}$

\footnotetext{
${ }^{23}$ Bajo esta denominación se pretende dar cuenta de cómo ha interpelado, modificado y profundizado la doctrina de los derechos humanos al derecho civil clásico. Se pasó de una cultura legalista, centrada en los textos legales como palabra última para resolver conflictos jurídicos, a una más flexible, plural, inclusiva y realista: la cultura constitucional/convencional. Ésta obliga revisar el derecho civil a la luz del desarrollo de los derechos humanos. Un claro ejemplo de este cambio de perspectiva es el mencionado Código Civil y Comercial argentino que en sus dos primeros artículos dispone en referencia al artículo 1, declara: "Los casos que este Código rige deben ser resueltos según las leyes que resulten aplicables, conforme con la Constitución Nacional y los tratados de derechos humanos en los que la República sea parte. A tal efecto, se tendrá en cuenta la finalidad de la norma. Los usos, prácticas y costumbres son vinculantes cuando las leyes o los interesados se refieren a ellos o en situaciones no regladas legalmente, siempre que no sean contrarios a derecho". El artículo 2 dedicado a la "Interpretación" afirma que "La ley debe ser interpretada teniendo en cuenta sus palabras, sus finalidades, las leyes análogas, las disposiciones que surgen de los tratados sobre derechos humanos, los principios y los valores jurídicos, de modo coherente con todo el ordenamiento".
} 
coloca a las normas civiles en su justo lugar. Para ello, se necesita un conocimiento integral del derecho que va más allá del derecho civil.

En este sentido, es dable destacar la bienvenida puesta en crisis que se observa desde hace varios años de la clásica clasificación (ya perimida) entre derecho público y derecho privado. En este contexto, es decir, siempre bajo el prisma de los derechos humanos, no todo vale. Precisamente, bajo esa misma lógica, hay decisiones jurisprudenciales que estarían en consonancia o en absoluta disonancia con ella. ¿Acaso extraer material genético post mortem, por una orden judicial y sin el correspondiente consentimiento informado de la persona se puede considerar una solución respetuosa de los derechos humanos?

Con la finalidad de sentar las bases sobre las cuales se debería elaborar la regulación en materia de fecundación post mortem, sin desvirtuar la noción de progresismo y pluralidad que, junto a la de laicidad, se debería volver a la fuente de la filiación en esta materia: la voluntad procreacional exteriorizada en el correspondiente consentimiento informado formal y específico o especial por encontrarse comprometidos derechos personalísimos. Esta debería ser la brújula que guíe el camino de cualquier regulación al respecto, siempre partiéndose de la aceptación de la FPM, es decir, de una mirada benigna en torno a ella, pero cuidada y bajo reglas claras.

Desde este contexto, fácilmente se advertiría que la resolución de la más reciente jurisprudencia argentina conculca dichos cimientos al apelar a la extraña noción de consentimiento presunto: la ausencia de consentimiento informado. Algo similar acontece en el caso londinense, donde también se carece de un consentimiento informado, máxime en una situación tan compleja como la que se describió. De mínima -más allá del abordaje interdisciplinario que es evidente en este tipo de planteos-, lo cierto es que no hubo ningún consentimiento informado, con las implicaciones que se derivan de ello.

Diferente sería el caso francés con repercusión directa en el derecho español, ya que la inseminación póstuma se haría en España por autorización judicial emitida del Consejo de Estado francés. Aquí sí se contó con consentimiento informado; incluso, se previó el traslado del material a ese otro país. Además, por la regulación prevista en la ley española 14/2006, se establece el plazo de un año para que se lleve adelante el procedimiento de transferencia. De esta manera, se asegura que la voluntad procreacional lo sea en el marco de un determinado proyecto parental. En el caso argentino donde la autorización judicial a la transferencia aconteció cinco años después del deceso ¿puede decirse que se mantiene el proyecto parental o corrobora más la imposibilidad o dificultad de hacer el duelo por la muerte de un hijo-marido? 
Reafirmar la importancia o el lugar central que ocupa la voluntad procreacional debidamente exteriorizada a través del consentimiento informado en el campo de la FPM, a la vez, permitirá brindar soluciones a planteamientos más complejos aún, como aquellos que entrecruzan este tipo de fertilización con otra, como la gestación por sustitución.

Si no se permite la fecundación post mortem porque se carece del consentimiento informado formal y específico, ¿ello implica la destrucción o donación para terceros o investigación del material o embriones conformados por gametos de una persona fallecida? La respuesta positiva se impondría. Ello no podría ser nunca tildado en abstracto como algo negativo porque, de hecho, las TRHA plantean dentro de su ámbito de actuación situaciones en las cuales se pierden o descartan gametos como embriones. Es más, esta situación podría ser adjetivada de "mal menor" si se toma en cuenta que del otro lado de la balanza está la carencia de voluntad procreacional materializada en el correspondiente consentimiento informado y formal, con el peso que tiene ello en las TRHA. Se agrega como elemento central la previsibilidad, es decir, el representarse la posibilidad de un eventual hecho trágico, como el fallecimiento.

En suma, como lo ha señalado George Bernard Shaw: "La ciencia nunca resuelve un problema sin crear otros diez más”. Bienvenidas las distintas voces jurisprudenciales provenientes de diferentes latitudes para mostrar y demostrar que la FPM ostenta varias facetas e involucra intereses y derechos sobre los cuales aún resta indagar. Si el presente ensayo aporta en esta línea, el objetivo está cumplido.

\section{Bibliografía}

"Application for permission to appeal against an order dismissing the appellants' claim for judicial review of a decision of the respondent, the Human Fertilisation and Embryology Authority, where the appellants had sought to have the gametes of their daughter exported to a treatment centre in New York", Family Law Week. [Consulta: 2 de julio, 2016]. Disponible en: http://www. familylawweek.co.uk/site.aspx?i=ed 159321

GiL DomíngueZ, AndRÉs, “El caso ‘Artavia Murillo II': la Corte Interamericana de Derechos Humanos determina con precisión la fuerza normativa de la convencionalidad aplicada a un caso concreto", Under Constitucional. [Consulta: 7 de septiembre, 2016]. Disponible en: http://underconstitucional.blogspot. com.ar/2016/04/el-caso-artavia-murillo-ii-la-corte.html

Herrera, Marisa, Reproducción artificial post mortem. Análisis del artículo 9 de la ley 14/2006 de 26 de mayo sobre Técnicas de Reproducción Humana Asistida, Valencia, Tirant lo Blanch, Valencia, 2013. 
"Judgment in proceedings challenging the decision by the HFEA to refuse permission to allow export and use of female gametes after death of the donor. Issues of consent, correct use of powers and engagement of Article 8", $\mathrm{Fa}$ mily Law Week. [Consulta: 2 de julio, 2016]. Disponible en: http://www.familylawweek.co.uk/site.aspx?i=ed 145462

Juzgado Civil, Com., Lab. y de Minería núm. 4 de Santa Rosa, La Pampa, 30 de diciembre, 2015, “A., C. V. c/ Instituto de Seguridad Social-Sempre S/ Amparo”, Colectivo Derecho de Familia. Disponible en: http://www.colectivoderechofamilia.com/fa-pcial-juz-1 ra-inst-civ-com-lab-y-mineria-no4-santa-rosala-pampa-fertilizacion-post-mortem/

Juzgado Nacional de 1a Instancia en lo Civil núm. 3, 3 de noviembre, 2014, "K. J. V. c. Instituto de Ginecología y Fertilidad y otros s/ amparo", La Ley.

Kemelmajer de Carlucci, Aida, Herrera, Marisa y lamm, Eleonora, "La Corte Interamericana de Derechos Humanos controla, sin concesión alguna, el cumplimiento de sus decisiones", La Ley, 2016.

““N. O. C. P. s/Autorización', Juzgado Nacional en lo Civil, No. 87, 05/05/2016”, El Dial. [Consulta: 10 de junio, 2016]. Disponible en: https://www.eldial.com/ nuevo/lite-jurisprudencia-detalle.. sp? $i d=39674 \mathrm{Ct}$ base $=14 \mathrm{Cth}=\mathrm{u}$

Rodriguez Guttian, Alma, "La reproducción artificial post mortem en España Estudio ante un nuevo dilema jurídico", Revista Boliviana de derecho, No. 20, pp. 292-323. [Consulta: 12 de julio, 2016]. Disponible en: http://idibe.org/ wp-content/uploads/2013/09/121.pdf

Tercera Cámara de Apelaciones en lo Civil, Comercial, Minas, de Paz y Tributario-Mendoza, “S., M. C. s. Medida autosatisfactiva”, Rubinzal Culzoni. Disponible en: http://www.rubinzalonline.com.ar/fallo/9702/

The National Archives, "Use of sperm, or transfer of embryo, after death of men providing sperm", Human Fertilization and Embryology Act 2008. Disponible en: http://www.legislation.gov.uk/ukpga/2008/22/section/39

“Tribunal Familiar núm. 3 Morón, 21 de noviembre de 2011, 'G., A. P.”, Revista de Derecho de Familia, No. 3, Buenos Aires, Abeledo Perrot, 2012. 
206 